\title{
ANÁLISE DA SUSCETIBILIDADE A ESCORREGAMENTOS A PARTIR DO ESTUDO DO RELEVO, COM APOIO DE SIG, NA BACIA DO ARROIO VEADO, RIO GRANDE DO SUL
}

\author{
Marinéli Moraes Gaberti ${ }^{(a)}$, Luís Eduardo de Souza Robaina ${ }^{(b)}$ \\ (a) Centro de Ciência Naturais e Exatas (CCNE)/Universidade Federal de Santa Maria E-mail: \\ marinelemorais@hotmail.com \\ ${ }^{(b)}$ Centro de Ciência Naturais e Exatas (CCNE)/Universidade Federal de Santa Maria'. E-mail: \\ lesrobaina@yahoo.com.br
}

\section{Eixo: GEOGRAFIA FÍSICA E DESASTRES NATURAIS}

\begin{abstract}
Resumo
Os movimentos de massa, são os principais processos de modificação do relevo, sendo assimneste artigo será apresentado uma análise de áreas topograficamente mais suscetíveis a escorregamentos translacionais a partir da utilização de SIG. Tendo como objetivo constatar que as áreas com maiores riscos de escorregamentos correspondem aos pontos mais inclinados do terreno.
\end{abstract}

Palavras Chave: Movimento de Massa, escorregamentos, SIG.

\section{Introdução}

Os movimentos de massa são um dos principais processos geomorfológicos responsáveis pela evolução do relevo, movimentando e remobilizando fragmentos de solo e rocha ao longo das encostas. Os Escorregamentos (landslides) são movimentos gravitacionais rápidos de curta duração, com volume e superfície de ruptura bem definidos, onde o material desprendido é jogado para fora da encosta, tendo como resultado, geralmente feições longas, como cicatrizes, podendo assumir geometria rotacional ou translacional.

Tais planos podem ser formados por antigas estruturas geológicas, geomorfológicas ou pedológicas, podendo ser compostos por rochas, solos residuais, talus, colúvio, detritos ou a mistura dos mesmos (GUIDICINI e NIEBLE, 1984; FERNANDES e AMARAL, 1996).

O desenvolvimento de métodos de geoprocessamento e SIG (Sistema de Informação Geográfica) ampliou a possibilidade de estudo da relação entre a topografia e os escorregamentos pois permitiu a representação da superfície terrestre na forma de modelos digitais numéricos, os quais possibilitam a análise topográfica de uma zona de interesse, assim como o cálculo automatizado de uma série de variáveis relacionadas.

Os fatores utilizados para estudos de escorregamentos, conforme Marina (2014) variam conforme o objetivo do trabalho, a escala, a metodologia utilizada, o tipo de movimento de massa em análise e as características da área estudada. A declividade foi considerada em todos os estudos analisados. 
Os atributos topográficos designados como perfil de curvatura e plano de curvatura. A primeira referese ao caráter convexo/côncavo do terreno, quando analisado em perfil ea segunda refere-se ao caráter divergente/convergente dos fluxos de matéria sobre o terreno quando analisado em projeção horizontal (VALERIANO, 2003).

Esses atributos, forma da encosta no perfil e no plano também influencia fortemente o desenvolvimento de movimentos de massa, uma vez que condiciona o fluxo de água e de materiais sólidos ao longo da mesma, o acúmulo de umidade e, em última análise, os níveis de poro-pressão desenvolvidos (FERNANDES e AMARAL, 2003).

O acúmulo de fluxo possui grande importância para a estabilização das encostas, uma vez que tem uma relação direta com a concentração dos fluxos de água superficial e subterrânea e consequente saturação dos solos (MONTGOMERY et al., 1998; DIETRICH et al., 1995).

Neste artigo será apresentado uma análise de áreas topograficamente mais suscetíveis a escorregamentos translacionais a partir da utilização de SIG e um modelo numérico do terrenoonde serão extraídos os parâmetros topográficas de declividade e forma da encosta na Bacia hidrográfica do Arroio Veado que localiza-se na região central do Rio Grande do Sul, entre as coordenadas geográficas $29^{\circ} 36^{\prime} 28^{\prime \prime}$ e $29^{\circ} 41^{\prime} 17^{\prime \prime}$ de latitude sul e 5339'19'” de longitude oeste, apresentando uma área de $48 \mathrm{~km}^{2}$.

\section{Metodologia}

Estudos sobre o comportamento da declividade em relação aos escorregamentos sugerem a existência de limites críticos desse parâmetro. Fernandes (1998) observa queopotencial de deslizamento cresce com o aumento dainclinação da encosta até $37,00-55,5^{\circ}$.

Brito (2014) utilizou declividades inferiores a 15\% como representando, de maneira geral, uma condição favorável à estabilidade, devido às baixas tensões de cisalhamento. Considerou-se esse valor como um marco a partir do qual os efeitos da declividade são mais significativos para a predisposição do terreno a esses processos.

Adicionalmente, consideraram-se as declividades de 35\% também como um limite, o que significa que não importa que a declividade tenha valores iguais a 35\%,40\% ou mais, ou seja, a suscetibilidade é igualmente alta. $\mathrm{O}$ motivo para isso é que, se por um lado declividades acentuadas favorecem a ruptura, por outro não propiciam a infiltração de água no solo, o que é decisivo para sua movimentação (OLIVEIRA e AUGUSTO FILHO, 2005). Para reescalonar esse fator foi utilizada uma função sigmoidal crescente, com pontos de inflexão da curva em 15\% (a função de pertinência começa a subir) e 35\% (a função atinge o valor 1). 
XVII Simpósio Brasileiro

de Geografia Fisica Aplicada

I Congresso Nacional

de Geografia Física

\section{OS DESAFIOS DA GEOGRAFIA FÍSICA NA FRONTEIRA DO CONHECIMENTO Instituto de Geociências - Unicamp Campinas - SP \\ 28 de Junho à 02 de Julho de 2017}

Para o limite superior considerou-se que uma encosta com declividade acima de 120\%, o processo de intemperismo e formação de solos é muito reduzido e, portanto, não gera escorregamentos translacionais. Nestas condições os movimentos de massa estariam associados a queda e tombamento de rochas. Portanto utilizou-se os seguintes limites de declividade: $<15 \%$ sem risco $-0 ; 15-30 \%$ risco baixo $-1 ; 30-60 \%$ risco médio $-2 ; 60-90 \%$ risco alto $-3 ; 90 \%-120 \%$ - risco muito alto $-4 ;>120 \%$ risco baixo -1 .

Com relação a forma da encosta, em geral, encostas divergentes e convexas são mais estáveis, seguido pelas encostas com segmentos planos e pelas encostas convergentes e côncavas, menos estáveis. Esses resultados atestam a importância da dinâmica hidrológica das encostas, com ênfase nos hollows, na geração de zonas de saturação no solos, onde poro-pressões elevadas são desenvolvidas, e sugerem que tais locais devam ser reconhecidos como áreas potencialmente instáveis, merecedoras de estudos de campo detalhados(VIEIRA et al., 1998;GUIMARÃES, 2000).

Dessa forma, o presente trabalho estabelece diferentes graus de suscetibilidade dependendo da forma da encosta. Usou-se 4 tipos de encostas: divergente-convexa - riso baixo 1; divergente-côncava-risco médio 2; convergente-convexa riscoalto 3; convergente-côncava risco muito alto 4.0 cruzamento dos valores de declividade e forma foram cruzados em uma matriz como a declividade tem sido o parâmetro mais importante utilizado em estudos de estabelecemos uma ponderação onde a declividade tem uma influência $2 \mathrm{X}$ maior que a forma, conforme representa a tabela 1.

Tabela 1-Cruzamentos e valores da declividade

\begin{tabular}{|l|l|l|l|l|}
\hline Decl/forma & 1 & 2 & 3 & 4 \\
\hline 2 & 2 & 4 & 6 & 8 \\
\hline 4 & 4 & 8 & 12 & 16 \\
\hline 8 & 8 & 16 & 24 & 32 \\
\hline 16 & 16 & 32 & 48 & 64 \\
\hline
\end{tabular}

Elaboração: O Autor (2017)

\section{Resultados}

Ao observar o mapa de suscetibilidade de escorregamento, a área sem risco de escorregamento corresponde a 1921,23 sendo 46,98\% da área total, a área com baixo risco de escorregamento corresponde a 1.193,21 ha, que equivale a $29,17 \%$ da área total, a área com médio risco de suscetibilidade a escorregamento é 692,07 há, que coincide a 16,89\% da área total, a que possui o nível alto de suscetibilidade a escorregamentos é de 258,97 ha que equivale a 6,34\%. O que possui muito risco ocupa uma área de 24,67 ha, que vale $0,62 \%$ da área total da bacia.Sendo assim, obteve-se como resultado que as áreas com maiores riscos de escorregamentos correspondem aos pontos mais inclinados do terreno, estando mais ou centro da bacia, conforme representa o mapa 1. 
Mapa1: Suscetibilidade de Escorregamento no Arroio Veado

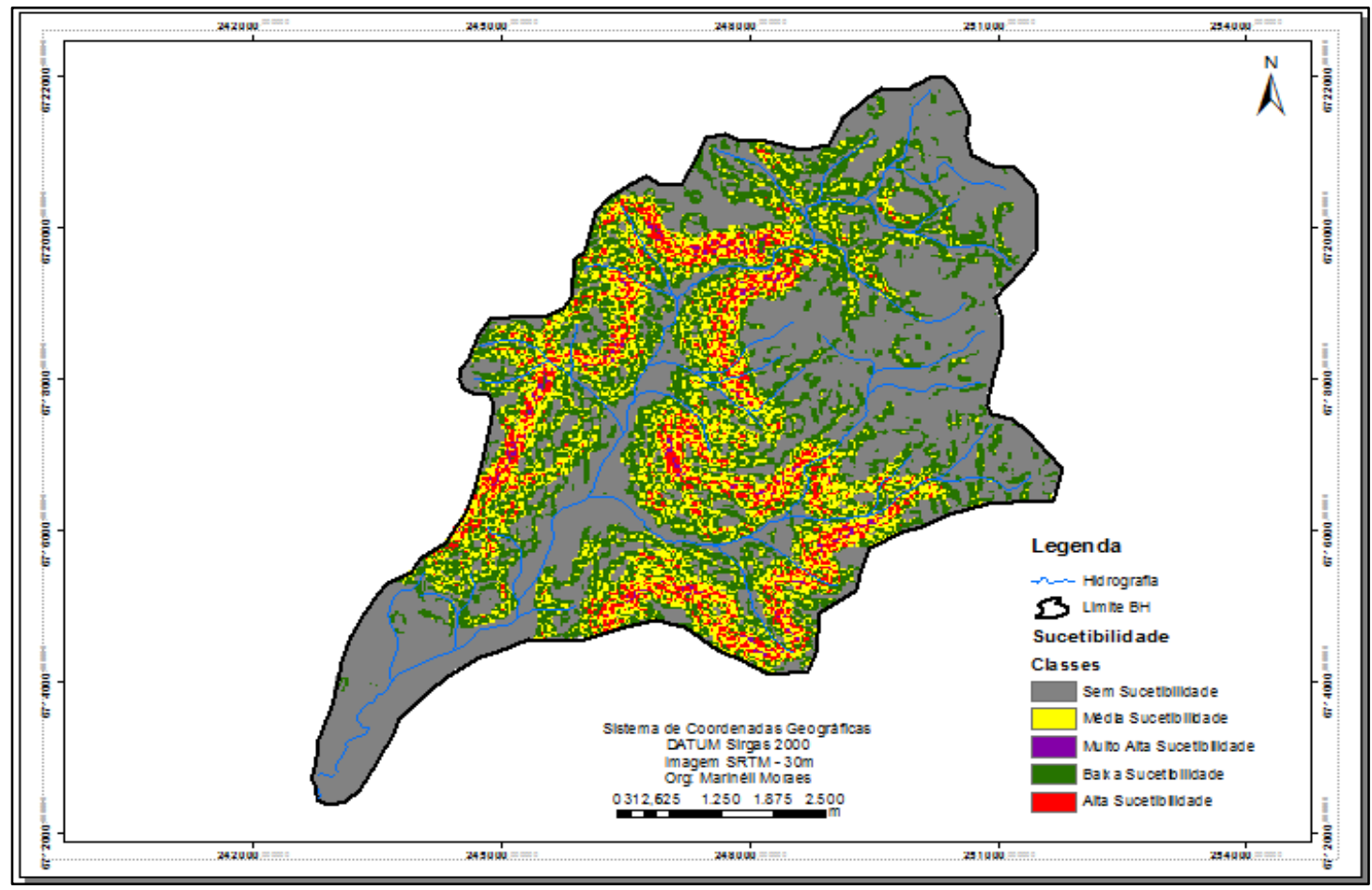

Elaboração: A Autora (2017).

\section{Conclusão}

É uma importante ferramenta de suporte na identificação e análise na intensidade e direção do fluxo da água na encosta.Além disso, o mapeamento da suscetibilidade permite orientar a execução de mapeamentos de risco em maior detalhe para os locais onde eles realmente são necessários.Acredita-se aqui que este modelo possui um enorme potencial de uso na definição de áreas instáveis em regiões onde as propriedades do solo são ainda pouco conhecidas, pelo menos a níveis de resolução próximos àqueles utilizados aqui para a desratização da topografia (grid de $2 \mathrm{~m} \times 2 \mathrm{~m}$ ), situação comum na grande maioria das situações.

Embora outros fatores estejam envolvidos na geração desses fenômenos (por ex. geológicos, antrópicos), acredita-se aqui que uma melhor investigação dos parâmetros morfológicos, com destaque para a forma da encosta e para a área de contribuição, possibilitada nos dias de hoje pela crescente disponibilidade de modelos digitais de terreno de alta resolução, levará a uma melhor compreensão dos mecanismos de ruptura envolvidos e uma previsão mais efetiva desses fenômenos em escalas regionais.

\section{Bibliografia}


BISPO, P. C.; ALMEIDA, C. M.; VALERIANO, M. M.; MEDEIROS,J. S.; CREPANI, E. Análise da suscetibilidade aos movimentos de massa em São Sebastião (SP) com o uso de métodos de inferência espacial. Geociências, v. 30, n. 3, p. 467-478, 2011.

CERRI, L. E. S.; AMARAL, C. P. (1998) RISCOS GEOLÓGICOS.IN OLIVEIRA, A.M.S. E BRITO,S.N.A. (eds.) Geologia de Engenharia.ABGE, São Paulo: 301-310.

FERNANDES, N. F. (1998) Avaliação estatística de parâmetros fit-morfológicos nas cicatrizes dos movimentos de massa da bacia do Rio Quitite, Jacarepaguá(RJ). XL Congresso Brasileiro de Geologia. SBG,Belo Horizonte, pp. 417.

FERNANDES, N. F.; AMARAL, C. P. (1996). Movimentos de massa: uma abordagem geológico geomorfológica. In Guerra, A.J.T. e Cunha, S.B. (org.) Geomorfologia e Meio Ambiente. Bertrand, Rio de Janeiro: 123-194.

FERNANDES, N. F.; AMARAL, C. P. Movimentos de massa: uma abordagem geológico-geomorfológica. In: GUERRA, A. J. T. E CUNHA, S. B. (org.) Geomorfologia e Meio Ambiente. $4^{a}$. ed. Rio de Janeiro: Bertrand, 2003. cap. 3, p. 123-194.

FERNANDES, N. F.; GUIMARÃES, R. F.; GOMES, R. A. T.; VIEIRA, B. C.; GUIDICINI, G.; NIEBLE, C. M. (1984) Estabilidade de taludes naturais e de escavação. EdgardBlücher, São Paulo.

GUIMARÃES, R. F. (2000) A modelagem matemática

MARIANA MADRUGA DE BRITO. Geoprocessamento Aplicado Ao Mapeamento Da Suscetibilidade A Escorregamentos No Município De Porto Alegre, Rs. Dissertação Apresentada Ao Programa De PósGraduação Em Engenharia Civil Da Universidade Federal Do Rio Grande Do Sul, Como Parte Dos Requisitos Para Obtenção Do Título De Mestre Em Engenharia. Porto Alegre. 2014. 155p.

MONTGOMERY, D. R.; SULLIVAN, K.; GREENBERG, M. H.(1998) Regional test of a model forshallowlandsliding. Hydrological Processes, 12:943-955.

na avaliação de áreas de risco a deslizamentos: o exemplo das bacias dos rios Quitite e Papagaio(RJ). Tese de Doutorado, Depto. de Geologia, UFRJ.

VIEIRA, B. C.; VIEIRA, A.C.F.; FERNANDES, N.F.;AMARAL, C.P.(1997) Estudo comparativo dos movimentos de massa ocorridos em Fevereiro de 1996 nas bacias do Quitite e Papagaio (RJ): uma abordagem geomorfológica. $\left.2^{\mathrm{a} C o n f e r e ̂ n c i a ~ B r a s i l e i r a ~ s o b r e ~ E s t a b i l i d a d e ~ d e ~ E n c o s t a s ~(~} 2^{\mathrm{a}} \mathrm{COBRAE}\right)$. ABMS, ABGE e ISSMGE. Rio de Janeiro: 165-174 